Article

\title{
New Briarane Diterpenoids from the Gorgonian Coral Junceella juncea
}

\author{
Jiun-Yang Chang ${ }^{1,2}$, Chia-Ching Liaw ${ }^{1}$, Ahmed Eid Fazary ${ }^{1}$, Tsong-Long Hwang ${ }^{3}$ and \\ Ya-Ching Shen ${ }^{1}$ *
}

1 School of Pharmacy, College of Medicine, National Taiwan University, Jen-Ai Rd. Sec. 1, Taipei 101-200, Taiwan; E-Mails: nomatter2200@ hotmail.com (J.-Y.C.);

biogodas@hotmail.com (C.-C.L.); aefazary@gmail.com (A.E.F.)

2 Institute of Marine Biotechnology and Resources, National Sun Yat-sen University, 70 Lien-Hai Road, Kaohsiung 80424, Taiwan

3 Graduate Institute of Natural Products, Chang Gung University, Taoyuan 333, Taiwan; E-Mail: htl@mail.cgu.edu.tw

* Author to whom correspondence should be addressed; E-Mail: ycshen@ntu.edu.tw; Tel.: +886-2-2312-3456 (ext. 62226); Fax: +886-2-2391-9098.

Received: 29 March 2012; in revised form: 18 May 2012 / Accepted: 29 May 2012 /

Published: 7 June 2012

\begin{abstract}
Chemical investigation of Junceella juncea has resulted in the isolation of three new briaranes designated juncenolides $\mathrm{M}-\mathrm{O}(\mathbf{1}-\mathbf{3})$. The structures of these compounds were determined by spectroscopic analysis including 2D-NMR (COSY, HMBC and NOESY) and HRMS. Compound $\mathbf{1}$ is a new chlorinated briarane while compound $\mathbf{3}$ contains a rare methyl ester at C-16. The anti-inflammatory activities tested on superoxide anion generation and elastase release by human neutrophils in response to FMLP/CB were evaluated.
\end{abstract}

Keywords: Junceella juncea; briaranes; anti-inflammatory activity

\section{Introduction}

Gorgonian corals of the genus Junceella (Ellisellidae) are common in subtropical and tropical waters in a number of places around the world, such as the South China Sea and Indo-Pacific Ocean, and are well known as a source of highly oxidized diterpenes of the briarane class (3,8-cyclized cembranoids) [1]. Many in vitro and in vivo studies on diterpenes isolated from gorgonians showed a variety of biological activities including anti-tumor, anti-inflammatory, antiplasmodial, antibacterial, antiviral, antimalarial 
and antioxidant, as well as ecologically relevant activities such as fish-feeding deterrence. Diterpenes isolated from gorgonian corals have a large structural diversity with 40 different diterpene classes being represented [2]. Recently, three new 8-hydroxybriarane diterpenoids (junceols A-C) and four new briarane diterpenoids (juncenolides $\mathrm{H}-\mathrm{K}$ ) were reported from a chemical investigation of Junceella juncea Pallas collected off the southern Taiwan coast, and some of these metabolites were found to exhibit inhibitory effects on superoxide anion generation and elastase release by human neutrophils [3,4]. Fourteen new briarane diterpenes, juncins O-ZII, were isolated from the EtOH/ $\mathrm{CH}_{2} \mathrm{Cl}_{2}$ extract of a South China Sea sample of $J$. juncea and some of them have been shown to exhibit potent antifouling and antifeedant activities [5-7]. A bioassay-guided fractionation of the acetone extract of a Taiwanese collection of $J$. juncea led to the identification of seven new diterpenoids, juncenolides A-G [8-11]. Moreover, a chemical investigation of the Indian Ocean gorgonian J. juncea resulted in the isolation of eight new briarane-type diterpenoids, juncins G-N [12-14]. A new briarane diterpenoid with antifungal activity was also isolated [15]. In continuation of our research programs oriented towards discovering new metabolites from the gorgonians collected off Taiwanese waters, we reinvestigated J. juncea. Examination of different chromatographic fractions of an AcOEt-soluble extract of the Taiwanese J. juncea Pallas resulted in the isolation of three new briaranes, designated juncenolides $\mathrm{M}-\mathrm{O}$ (1-3) (Figure 1). Their structures were elucidated through detailed spectroscopic analyses, mainly 2D NMR experiments $\left({ }^{1} \mathrm{H},{ }^{1} \mathrm{H}\right.$ COSY, HQMC, HMBC). The relative stereochemistry of the chiral centers and the geometry of the double bonds were deduced from NOESY spectra.

Figure 1. Structures of compounds 1-3.

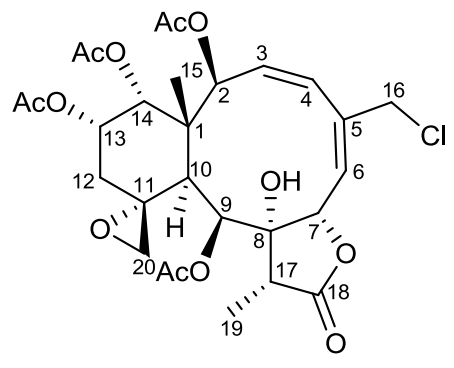

1

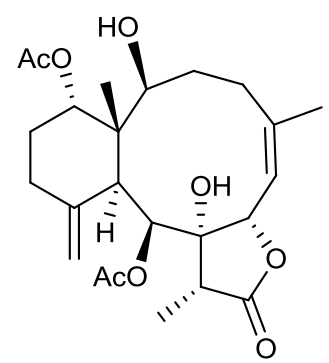

2

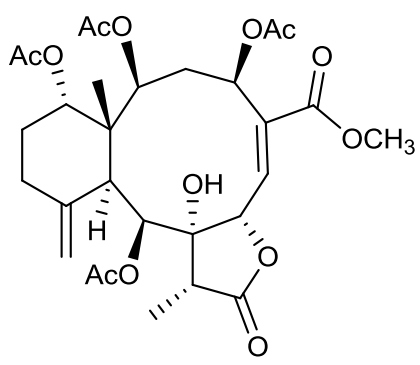

3

\section{Results and Discussion}

Compound 1 was isolated as a colorless amorphous solid. The molecular formula was determined to be $\mathrm{C}_{28} \mathrm{H}_{35} \mathrm{ClO}_{12}$ (11 degrees of unsaturation) from the HR-ESI-MS data $\left(\mathrm{m} / z\right.$ 621.1711 $\left.\left([\mathrm{M}+\mathrm{Na}]^{+}\right)\right)$, which also showed a $M+2$ peak at $m / z 623.1685$ (3:1), indicating the presence of one chlorine atom. Its IR bands revealed the presence of a hydroxyl group $\left(3402 \mathrm{~cm}^{-1}\right)$, a five-membered lactone $\left(1779 \mathrm{~cm}^{-1}\right)$ and ester groups $\left(1741 \mathrm{~cm}^{-1}\right) .{ }^{1} \mathrm{H}$ - and ${ }^{13} \mathrm{C}-\mathrm{NMR}$ data (Tables 1 and 2 ) indicated the presence of four acetates $\left(\delta_{\mathrm{H}} 2.18, \mathrm{~s} ; 2.07, \mathrm{~s} ; 1.97, \mathrm{~s} ; 1.95, \mathrm{~s}\right)$ and $\delta_{\mathrm{C}} 170.2 \times 2 ; 170.0 \times 2 ; 21.6 ; 21.3 ; 21.0$; 20.8 , one carbonyl carbon $\left(\delta_{\mathrm{C}} 175.3\right)$, and two double bonds $\left(\delta_{\mathrm{C}} 126.1 ; 128.1 ; 131.7 ; 140.0\right)$, suggesting four rings in the structure. The protons of $\mathrm{CH}_{2}-20\left(\delta_{\mathrm{H}} 3.54\right.$, br. s; 2.74 , br. $\left.s\right)$, its corresponding carbon $\left(\delta_{\mathrm{C}} 50.2\right)$ and the quaternary carbon at $\delta_{\mathrm{C}} 58.1$, were assigned to an exocyclic epoxide [16]. The presence of a $\gamma$-lactone ring was ascertained by the carbonyl carbon at $\delta_{\mathrm{C}} 175.3(\mathrm{C}-18)$, and the $O$-bearing carbons at $\delta_{\mathrm{C}} 78.5(\mathrm{C}-7)$ and $81.2(\mathrm{C}-8)$, and confirmed the HMBC correlations (Figure 2) of Me-19/C-8, C-17, 
C-18 and C-7/C-8, C-18 [16,17]. Four OAc groups were attached to C-2, C-9, C-13 and C-14 by the observation of HMBC correlations (Figure 2$)$. A tertiary methyl signal $\left(\delta_{\mathrm{H}} 1.09\right.$, Me-15) correlated with a quaternary carbon (C-1), two oxymethines at $\delta_{\mathrm{C}} 74.2$ and 73.8, and the $\mathrm{CH}$ at $\delta_{\mathrm{C}} 41.4$, (C-10), implying oxygenation at C-2 and C-14. HMBC correlations of Me-15/C-1, C-2, C-10, C-14, CH $2-16 / \mathrm{C}-4, \mathrm{C}-5$, C-6, CH-7/C-5, C-8, C-18, CH-9/C-8, C-11, and CH-10/C-1, C-8, C-11, C-20, as well as ${ }^{1} \mathrm{H}-{ }^{1} \mathrm{H}$ COSY connectivities between $\mathrm{CH}-2 / \mathrm{CH}-3 / \mathrm{CH}-4, \mathrm{CH}-6 / \mathrm{CH}-7, \mathrm{CH}-9 / \mathrm{CH}-10, \mathrm{CH}_{2}-12 / \mathrm{CH}-13 / \mathrm{CH}-14$ (Figure 1), suggested that compound 1 possesses 8-hydroxybriarane-type diterpenoid skeleton together with an exocyclic epoxy group which was corroborated by $\mathrm{HMBC}$ correlations of $\mathrm{CH}_{2}-12 / \mathrm{C}-11$, C-20.

Table 1. ${ }^{1} \mathrm{H}$ NMR Data of Compounds $\mathbf{1}-\mathbf{3} . \delta$ in ppm, $J$ in $\mathrm{Hz}$.

\begin{tabular}{|c|c|c|c|}
\hline Position & $\mathbf{1}^{\mathrm{a}}$ & $2^{b}$ & $3^{b}$ \\
\hline 2 & $5.37(\mathrm{~d}, J=9.6)$ & 4.94 (overlap) & $4.86(\mathrm{~d}, J=7.6)$ \\
\hline \multirow[t]{2}{*}{3} & $5.62(\mathrm{t}, J=9.6)$ & $1.74-1.78(\mathrm{~m})$ & $2.13-2.16(\mathrm{~m})$ \\
\hline & & $2.46-2.50(\mathrm{~m})$ & $2.72(\mathrm{t}, J=10.0)$ \\
\hline \multirow[t]{2}{*}{4} & $6.35(\mathrm{~d}, J=9.6)$ & $2.19-2.15(\mathrm{~m})$ & $5.91-5.94(\mathrm{~m})$ \\
\hline & & 2.64 (br. d, $J=13.6$ ) & \\
\hline 6 & $6.00(\mathrm{~d}, J=9.0)$ & $5.67(\mathrm{~d}, J=10.4)$ & $7.06(\mathrm{~d}, J=10.0)$ \\
\hline 7 & $4.95(\mathrm{~d}, J=9.0)$ & $5.26(\mathrm{~d}, J=10.4)$ & $5.62(\mathrm{~d}, J=10.0)$ \\
\hline 9 & $4.71(\mathrm{~d}, J=4.8)$ & $5.31(\mathrm{~d}, J=6.0)$ & $5.56(\mathrm{~d}, J=2.8)$ \\
\hline 10 & $3.04(\mathrm{~d}, J=4.8)$ & $3.45(\mathrm{~d}, J=6.0)$ & $3.25(\mathrm{~d}, J=2.8)$ \\
\hline \multirow[t]{2}{*}{12} & $1.34-1.38(\mathrm{~m})$ & $2.16-2.19(\mathrm{~m})$ & $2.18-2.23(2 \mathrm{H}, \mathrm{m})$ \\
\hline & $2.48(\mathrm{~d}, J=14.0)$ & $2.34-2.36(\mathrm{~m})$ & \\
\hline \multirow[t]{2}{*}{13} & 4.96 (overlap) & $1.82-1.86(\mathrm{~m})$ & $1.80-1.87(2 \mathrm{H}, \mathrm{m})$ \\
\hline & & $1.97-1.99(\mathrm{~m})$ & \\
\hline 14 & 5.20 (br. s) & 4.59 (br. s) & 4.69 (br. s) \\
\hline 15 & $1.09(\mathrm{~s})$ & $1.12(\mathrm{~s})$ & $1.03(\mathrm{~s})$ \\
\hline 16 & $4.58(2 \mathrm{H}, \mathrm{s})$ & $2.05(\mathrm{~s})$ & - \\
\hline 17 & $2.26(\mathrm{q}, J=6.9)$ & $2.46(\mathrm{q}, J=6.8)$ & $2.63(\mathrm{q}, J=6.8)$ \\
\hline 19 & $1.13(\mathrm{~d}, J=6.9)$ & $1.11(\mathrm{~d}, J=6.8)$ & $1.19(\mathrm{~d}, J=6.8)$ \\
\hline \multirow[t]{2}{*}{20} & 2.74 (br. s) & $4.92(\mathrm{~s})$ & $4.95(\mathrm{~s})$ \\
\hline & 3.54 (br. s) & $5.05(\mathrm{~s})$ & $5.05(\mathrm{~s})$ \\
\hline AcO-2 & $1.95(\mathrm{~s})$ & - & $1.97(\mathrm{~s})$ \\
\hline $\mathrm{AcO}-4$ & - & - & $2.06(\mathrm{~s})$ \\
\hline AcO-9 & $2.18(\mathrm{~s})$ & $2.20(\mathrm{~s})$ & $2.21(\mathrm{~s})$ \\
\hline AcO-13 & $2.07(\mathrm{~s})$ & - & - \\
\hline AcO-14 & $1.97(\mathrm{~s})$ & $1.92(\mathrm{~s})$ & $1.90(\mathrm{~s})$ \\
\hline OMe-16 & - & - & $3.83(\mathrm{~s})$ \\
\hline
\end{tabular}

${ }^{\mathrm{a}}$ Recorded in $\mathrm{CDCl}_{3}$ at $300 \mathrm{MHz} ;{ }^{\mathrm{b}}$ Recorded in $\mathrm{CDCl}_{3}$ at $400 \mathrm{MHz}$.

Table 2. ${ }^{13} \mathrm{C}$-NMR Data of Compounds $\mathbf{1}-\mathbf{3} . \delta$ in ppm.

\begin{tabular}{cccc}
\hline Position & $\mathbf{1}^{\mathbf{a}}$ & $\mathbf{2}^{\mathbf{b}}$ & $\mathbf{3}^{\mathbf{b}}$ \\
\hline 1 & $46.5(\mathrm{~s})$ & $46.9(\mathrm{~s})$ & $47.8(\mathrm{~s})$ \\
2 & $74.2(\mathrm{~d})$ & $75.7(\mathrm{~d})$ & $72.1(\mathrm{~d})$ \\
3 & $131.7(\mathrm{~d})$ & $31.3(\mathrm{t})$ & $37.3(\mathrm{t})$ \\
4 & $128.1(\mathrm{~d})$ & $29.2(\mathrm{t})$ & $67.4(\mathrm{~d})$ \\
5 & $140.0(\mathrm{~s})$ & $144.8(\mathrm{~s})$ & $136.8(\mathrm{~s})$ \\
6 & $126.1(\mathrm{~d})$ & $120.5(\mathrm{~d})$ & $139.1(\mathrm{~d})$ \\
7 & $78.5(\mathrm{~d})$ & $77.8(\mathrm{~d})$ & $76.7(\mathrm{~d})$ \\
\hline
\end{tabular}


Table 2. Cont.

\begin{tabular}{cccc}
\hline 8 & $80.8(\mathrm{~s})$ & $83.0(\mathrm{~s})$ & $82.9(\mathrm{~s})$ \\
9 & $64.3(\mathrm{~d})$ & $71.3(\mathrm{~d})$ & $72.7(\mathrm{~d})$ \\
10 & $35.7(\mathrm{~d})$ & $41.8(\mathrm{~d})$ & $42.6(\mathrm{~d})$ \\
11 & $58.1(\mathrm{~s})$ & $150.8(\mathrm{~s})$ & $150.5(\mathrm{~s})$ \\
12 & $34.3(\mathrm{t})$ & $26.3(\mathrm{t})$ & $29.2(\mathrm{t})$ \\
13 & $67.7(\mathrm{~d})$ & $26.9(\mathrm{t})$ & $27.5(\mathrm{t})$ \\
14 & $73.8(\mathrm{~d})$ & $74.5(\mathrm{~d})$ & $74.0(\mathrm{~d})$ \\
15 & $14.4(\mathrm{q})$ & $15.4(\mathrm{q})$ & $14.4(\mathrm{q})$ \\
16 & $44.7(\mathrm{t})$ & $27.2(\mathrm{q})$ & $166.6(\mathrm{~s})$ \\
17 & $43.9(\mathrm{~d})$ & $42.5(\mathrm{~d})$ & $43.3(\mathrm{~d})$ \\
18 & $175.3(\mathrm{~s})$ & $175.9(\mathrm{~s})$ & $175.3(\mathrm{~s})$ \\
19 & $6.3(\mathrm{q})$ & $6.5(\mathrm{q})$ & $6.4(\mathrm{q})$ \\
20 & $50.2(\mathrm{t})$ & $113.3(\mathrm{t})$ & $113.3(\mathrm{t})$ \\
$\mathrm{AcO}-2$ & $170.2(\mathrm{~s})$ & - & $169.9(\mathrm{~s})$ \\
& $20.8(\mathrm{q})$ & & $20.8(\mathrm{q})$ \\
$\mathrm{AcO}-4$ & - & - & $169.6(\mathrm{~s})$ \\
& & & $21.2(\mathrm{q})$ \\
$\mathrm{AcO}-9$ & $170.0(\mathrm{~s})$ & $169.3(\mathrm{~s})$ & $169.2(\mathrm{~s})$ \\
& $21.6(\mathrm{q})$ & $21.7(\mathrm{q})$ & $21.7(\mathrm{q})$ \\
$\mathrm{AcO}-13$ & $170.0(\mathrm{~s})$ & - & - \\
& $21.3(\mathrm{q})$ & & $170.5(\mathrm{~s})$ \\
AcO-14 & $170.2(\mathrm{~s})$ & $170.4(\mathrm{~s})$ & $21.1(\mathrm{q})$ \\
& $21.0(\mathrm{q})$ & $21.2(\mathrm{q})$ & $52.8(\mathrm{q})$ \\
OMe-16 & - & - & \\
\hline
\end{tabular}

${ }^{\mathrm{a}}$ Recorded in $\mathrm{CDCl}_{3}$ at $75 \mathrm{MHz} ;{ }^{\mathrm{b}}$ Recorded in $\mathrm{CDCl}_{3}$ at $100 \mathrm{MHz}$.

Figure 2. Key ${ }^{1} \mathrm{H}-{ }^{1} \mathrm{H}$ COSY and HMBC correlations of 1-3.

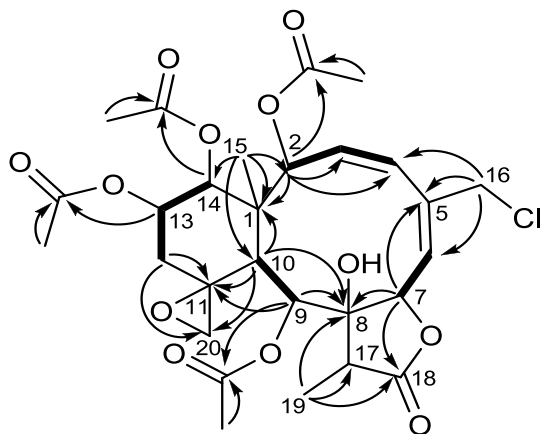

1

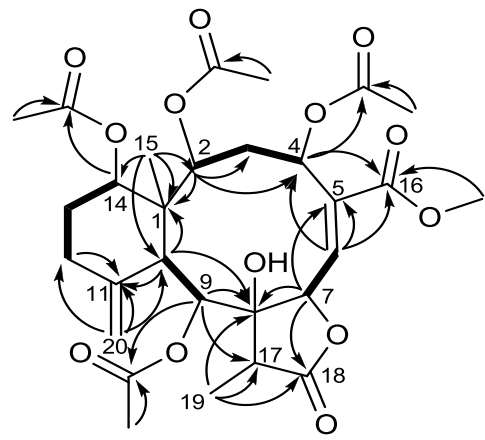

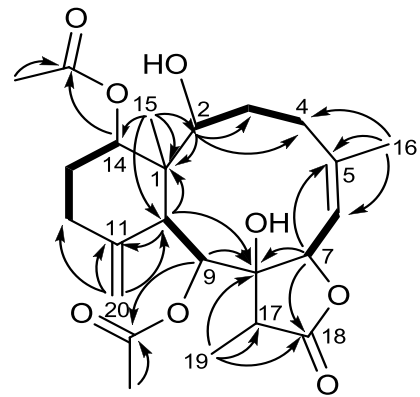

2

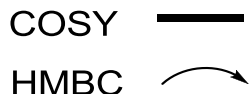

$\mathrm{HMBC}$ 
The relative configuration of 1 was determined on the basis of NOESY experiment, MM2 minimized energy calculated molecular modeling (Figure 3), and comparison with other naturally occurring briarane diterpenoids. Briarane-type diterpenoids were previously reported to contain the $\mathrm{Me}-15$ in the $\beta$-orientation and $\mathrm{H}-10$ in the $\alpha$-orientation. As expected, there is no NOE correlation between $\mathrm{CH}-10$ and Me-15. The orientations of $\mathrm{CH}-10$ and the methyl group Me-15 should be opposite. According to MM2 study, we thus concluded that compound 1 had the $\mathrm{Me}-15$ in the $\beta$-orientation and $\mathrm{CH}-10$ in the $\alpha$-orientation as reported [18]. NOESY correlations of $\mathrm{CH}-10 / \mathrm{H}-2, \mathrm{CH}-9, \mathrm{CH}_{\alpha}-12, \mathrm{Me}-15 / \mathrm{CH}_{2}-20$, $\mathrm{CH}-14, \mathrm{CH}_{2}-20 / \mathrm{CH}-13, \mathrm{CH}_{\beta}-12$ and $\mathrm{CH}-14 / \mathrm{CH}-13$ suggested the $\beta$-orientation of $\mathrm{CH}-13$ and $\mathrm{CH}-14$ and $\alpha$-orientation of $\mathrm{CH}-2$ and $\mathrm{CH}-9$, a $\beta$-oriented exocyclic epoxy group attached to cyclohexane moiety as previously assigned from the ${ }^{1} \mathrm{H}$ - and ${ }^{13} \mathrm{C}$ NMR data of $\mathrm{C}-11$ and $\mathrm{C}-20$ [19] and the $\alpha$-orientation of $\mathrm{CH}-2$. The cis configuration of the $\mathrm{C}-3 / \mathrm{C}-4$ double bond was suggested by the NOESY correlations (Figure 3) between $\mathrm{CH}-3 / \mathrm{CH}-4$ and the $J$ value $(9.6 \mathrm{~Hz})$. Compound 1 appears to be the chlorinated derivative of juncenolide B isolated from the same species previously [9]. They have the same configuration of chiral centers. Based on the above interpretation, compound $\mathbf{1}$ is a new chlorinated briarane-type diterpene designated juncenolide $\mathrm{M}$.

Figure 3. Key NOESY correlations of compounds $\mathbf{1}-\mathbf{3}$ in molecular modeling.

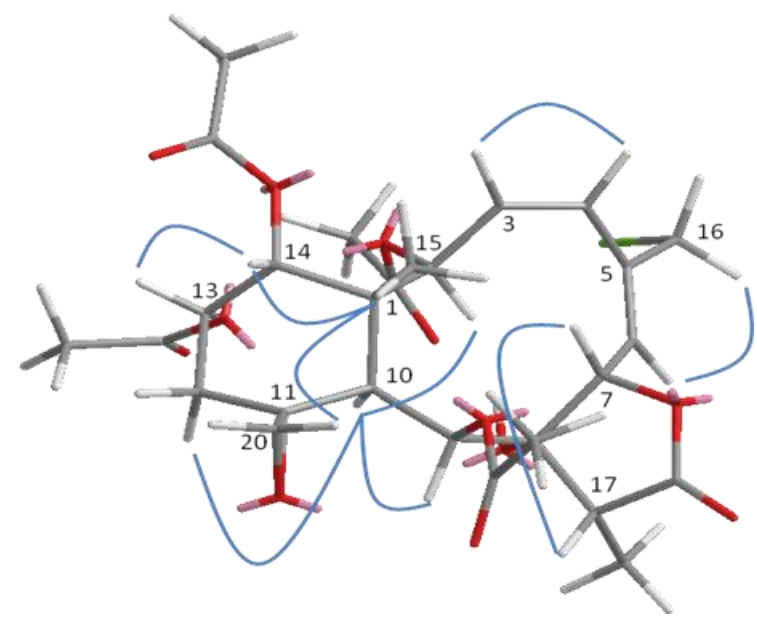

1

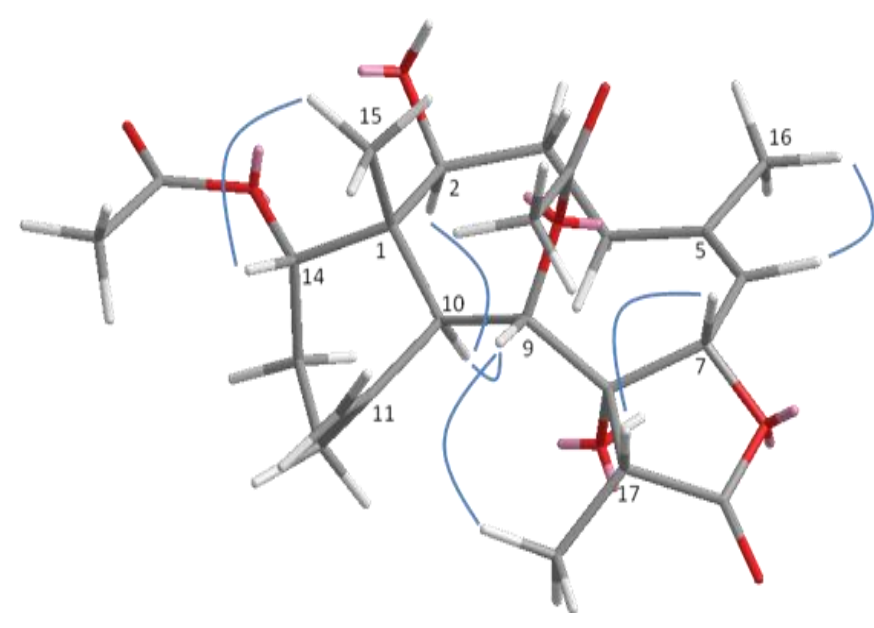

2

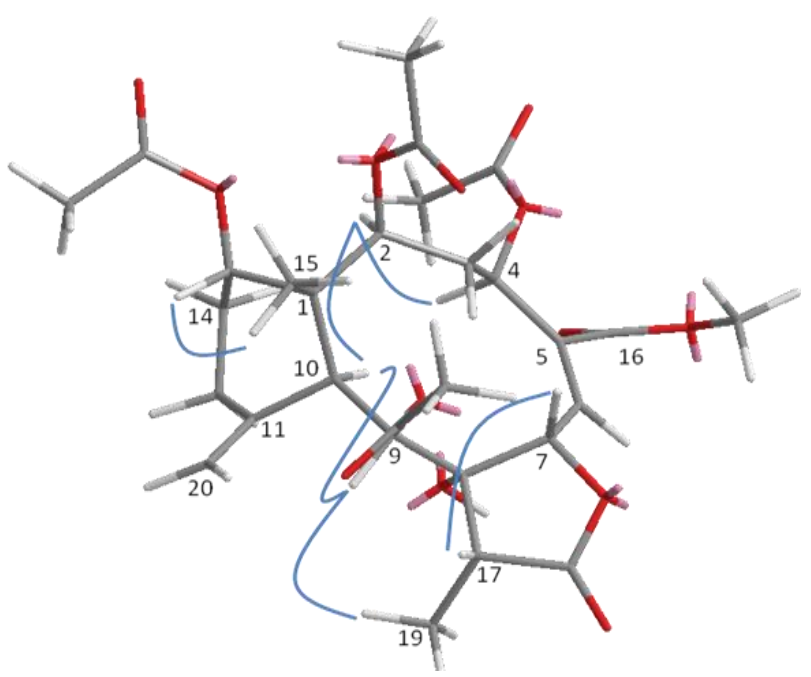


Compound 2, isolated as a colorless solid, and had a molecular formula of $\mathrm{C}_{24} \mathrm{H}_{34} \mathrm{O}_{8}$, deduced from HR-ESI-MS at $m / z 473.2155\left([\mathrm{M}+\mathrm{Na}]^{+}\right)$, showing eight degrees of unsaturation. The presence of hydroxyl, a $\gamma$-lactone ring, and ester groups were consistent with IR absorptions at 3481,1772 and $1732 \mathrm{~cm}^{-1}$. The ${ }^{1} \mathrm{H}$ and ${ }^{13} \mathrm{C}$ NMR (Tables 1 and 2$)$, revealed the presence of an exomethylene $\left(\delta_{\mathrm{C}} 150.8\right.$, 113.3), one trisubstituted double bond $\left(\delta_{\mathrm{C}} 144.8,120.5\right)$, two OAc carbonyl $(\mathrm{C}=\mathrm{O})\left(\delta_{\mathrm{C}} 170.4,169.3\right)$ and one $\gamma$-lactone carbonyl $(\mathrm{C}=\mathrm{O})\left(\delta_{\mathrm{C}} 175.9\right)$, which accounted for five degrees of unsaturation and were suggestive of a tricyclic briarane bearing a $\gamma$-lactone ring. The carbonyl signal at $\delta_{\mathrm{C}} 175.9(\mathrm{C}-18)$ was ascribed to a $\gamma$-lactone ring with the oxymethine at $\delta_{\mathrm{C}} 78.3(\mathrm{C}-7)$ and the $O$-bearing quaternary carbon at $\delta_{\mathrm{C}} 82.2(\mathrm{C}-7)$. The proton singlets at $\delta_{\mathrm{H}} 5.05$ and $4.92\left(\delta_{\mathrm{C}} 113.3\right)$ were assigned to the exocyclic methylene group and correlated to C-10, C-12, and C-11 in the HMBC spectrum (Figure 2), suggesting the presence of a C-11/C-20 double bond. HMBC correlations of Me-15/C-1, C-2, C-14, C-10, $\mathrm{Me}-16 / \mathrm{C}-4, \mathrm{C}-5$, C-6, CH-7/C-5, C-8, C-18, CH-9/C-8, CH-10/C-11, C-1, C8 and the ${ }^{1} \mathrm{H},{ }^{1} \mathrm{H}$ COSY correlations of $\mathrm{CH}-2 / \mathrm{CH}_{2}-3 / \mathrm{CH}_{2}-4, \mathrm{CH}-6 / \mathrm{CH}-7, \mathrm{CH}-9 / \mathrm{CH}-10, \mathrm{CH}_{2}-12 / \mathrm{CH}_{2}-13 / \mathrm{CH}-14$ revealed the tricyclic skeleton of $\mathbf{2}$. Furthermore, two OAc groups positioned at $\mathrm{C}-9$ and $\mathrm{C}-14$ were established by the key correlations observed in the HMBC spectrum of 2. NOESY experiment revealed that the absence of correlation between and suggested orientation of and disposition of compound 2. The NOESY correlations (Figure 3) between Me-15/CH-14; CH-10/CH-2, CH-9, CH-9/Me-19, and CH-7/CH-17 were in agreement with the $\beta$-orientation of $\mathrm{CH}-7, \mathrm{CH}-14$ and $\mathrm{CH}-17$, and $\alpha$-orientation of $\mathrm{CH}-2, \mathrm{CH}-9$ and Me-19. Therefore, compound $\mathbf{2}$ is a new tricyclic briarane bearing a $\gamma$-lactone ring, and was given the name of juncenolide $\mathrm{N}$.

The molecular formula of 3 was established as $\mathrm{C}_{29} \mathrm{H}_{38} \mathrm{O}_{13}$ from the molecular peak at $\mathrm{m} / z, 617.2212$ $[\mathrm{M}+\mathrm{Na}]^{+}$in the HR-ESI-MS. The NMR data (Tables 1 and 2) revealed the basic features of a 8-hyoxybriarane type diterpenoid with a $\gamma$-lactone, one exomethylene double bond, one trisubstituted double bond (Tables 1 and 2), and four acetate esters. The C-20/C-11 exomethylene double bond was assigned with the aid of HMBC correlations of $\mathrm{CH}_{2}-20 / \mathrm{C}-10, \mathrm{C}-11, \mathrm{C}-12$. The signal of CH-6 showed correlations to C-4, C-5 and C-16 in HMBC, revealing the C-5/C-6 trisubstituted double bond, and a COOMe group attached to C-5 (Figure 2). The four acetates were deduced to be located at C-2, C-4, C-9, and $\mathrm{C}-14$ by HMBC correlations of the oxymethines at $\delta_{\mathrm{H}} 4.86(\mathrm{CH}-2), 5.93(\mathrm{CH}-4), 5.56(\mathrm{CH}-13)$, and $4.69(\mathrm{CH}-14)$ to their respective acetate carbonyls. The ${ }^{1} \mathrm{H},{ }^{1} \mathrm{H}$ COSY connectivities (Figure 2) of $\mathrm{CH}-2 / \mathrm{CH}_{2}-3 / \mathrm{CH}-4, \mathrm{CH}-6 / \mathrm{CH}-7, \mathrm{CH}-9 / \mathrm{CH}-10, \mathrm{CH}_{2}-12 / \mathrm{CH}_{2}-13 / \mathrm{CH}-14$, as well as HMBC correlations of Me-15/C-1, C-2, C-10, C-14, CH-4/C-16, CH-7/C-8, C-18, CH-9/C-8, C-17, CH-10/C-1, C-8, C-11, $\mathrm{CH}_{2}-12 / \mathrm{C}-11$ and $\mathrm{Me}-19 / \mathrm{C}-8, \mathrm{C}-17, \mathrm{C}-18$, confirmed the tricyclic skeleton of 3 . The NOESY experiments (Figure 3 ) showed the relative configuration of compound 3 . Due to the $\alpha$-orientation of $\mathrm{CH}-10$, the methyl group Me-15 at the ring junction should be $\beta$-oriented as no NOE correlation was observed between $\mathrm{CH}-10$ and Me-15. NOESY spectrum clearly displayed the interactions between Me-15/CH-14, CH-10/CH-9, CH-2, CH-2/CH-4, and CH-9/CH-19, indicating that the OAc at C-2, C-4 and $\mathrm{C}-9$ are $\beta$-oriented, whereas the $\mathrm{OAc}$ at $\mathrm{C}-14$ is in the $\alpha$-position. Thus, compound $\mathbf{3}$ is a new briarane ester with a $\gamma$-lactone skeleton, and designated juncenolide $\mathrm{O}$.

The isolated briaranes 1-3 were tested on inhibitory effects of superoxide anion generation and elastase release by human neutrophils in response to FMLP/CB at a concentration of $10 \mu \mathrm{g} / \mathrm{mL}$. As illustrated in Table 3, compounds $\mathbf{2}$ and $\mathbf{3}$ showed moderate inhibitory activities against elastase release 
with $29.0 \pm 5.6 \%$, and $35.9 \pm 7.4 \%$, respectively. Furthermore, compound 3 also exhibited moderate inhibitory activity against superoxide anion with $27.6 \pm 7.0 \%$.

Table 3. Effects of compounds $\mathbf{1}-\mathbf{3}$ on superoxide anion generation and elastase release by human neutrophils in response to FMLP/CB ${ }^{\text {a }}$.

\begin{tabular}{ccc}
\hline \multirow{2}{*}{ Compounds } & Superoxide anion & Elastase release \\
\cline { 2 - 3 } & Inhibition $(\%)^{\mathrm{b}}$ & Inhibition $(\%)$ \\
\hline $\mathbf{1}$ & $7.6 \pm 2.8$ & $15.9 \pm 5.5$ \\
$\mathbf{2}$ & $6.7 \pm 2.9$ & $29.0 \pm 5.6$ \\
$\mathbf{3}$ & $27.6 \pm 7.0$ & $35.9 \pm 7.4$ \\
Genistein & $65.0 \pm 5.7$ & $51.6 \pm 5.9$ \\
\hline
\end{tabular}

${ }^{\mathrm{a}}$ Results are presented as mean \pm S.E.M. $(n=3)$; ${ }^{\mathrm{b}}$ Percent of inhibition at $10 \mu \mathrm{g} / \mathrm{mL}$.

\section{Experimental Section}

\subsection{General}

Column chromatography (CC); silica gel 60 (Merck, Darmstadt, Germany) and Sephadex LH-20 (Amersham Pharmacia Biotech AB, Uppsala, Sweden). Prep. TLC: pre-coated silica gel plates (Merck; silica gel 60 F-254, 1 mm). LiChrospher Si 60 (5 $\mu \mathrm{m}, 250-10$, Merck) and LiChrospher 100 RP-18e (5 $\mu \mathrm{m}, 250-10$, Merck) were used for NP-HPLC and RP-HPLC (Merck, Darmstadt, Germany), respectively. Spray reagent: $p$-anisaldehyde reagent with $5 \% \mathrm{H}_{2} \mathrm{SO}_{4}$. Optical rotations: Jasco DIP-1000 polarimeter. UV Spectra: Hitachi U-3210 spectrometer; $\lambda_{\max }(\log \varepsilon)$ in nm. IR Spectra: Hitachi T-2001 spectrometer; in $\mathrm{cm}^{-1} .{ }^{1} \mathrm{H}-,{ }^{13} \mathrm{C}-\mathrm{NMR}$, COSY, HMQC, HMBC, and NOESY experiments: Bruker Avance 300 NMR spectrometer or Varian MR $400 \mathrm{NMR}$ spectrometer, $\mathrm{SiMe}_{4}$ as internal standard; $\delta$ in ppm, coupling constants $J$ in Hz. LRESIMS and HRESIMS: JEOL JMS-HX 110 mass spectrometer; in $\mathrm{m} / z$.

\subsection{Animal Material}

The gorgonian Junceella juncea Pallas (Ellisellidae) was collected in Tai-Tong County, Taiwan, by scuba diving at a depth of $15 \mathrm{~m}$, in November 2006. The fresh gorgonian was immediately frozen after collection and kept at $-20{ }^{\circ} \mathrm{C}$ until processed. This species was identified by one of the authors (C.-C.L). A voucher specimen (WSG-5) was deposited in the School of Pharmacy, College of Medicine, National Taiwan University, Taiwan.

\subsection{Extraction and Isolation}

The outer grey layer of the gorgonian $(1.4 \mathrm{~kg}$, wet weight $)$ was extracted with acetone $(3 \times 500 \mathrm{~mL})$ at r.t., and the acetone extract was concentrated under vacuum. The crude extract $(8 \mathrm{~g})$ was partitioned between AcOEt and $\mathrm{H}_{2} \mathrm{O}$ (1:1). The AcOEt-soluble portion (4.9 g) was subjected to column chromatography $\left(\mathrm{SiO}_{2}, n\right.$-Hexane/AcOEt 10:1-0:1; TLC $\left(\mathrm{GF}_{254}\right)$ monitoring) giving fractions 1-16. Fr. $12(195 \mathrm{mg})$ was subjected to a NP-HPLC $\left(\mathrm{CH}_{2} \mathrm{Cl}_{2} / \mathrm{MeOH}, 150: 1\right)$, affording Fr. 12a (12 mg) which was further purified by RP-HPLC $\left(\mathrm{MeOH} / \mathrm{H}_{2} \mathrm{O} / \mathrm{CH}_{3} \mathrm{CN}, 70: 25: 5\right)$ yielding compound 1 (6 mg). Fr. 16 (105 mg) was separated by NP-HPLC $\left(\mathrm{CH}_{2} \mathrm{Cl}_{2} / \mathrm{MeOH}, 80: 1\right)$, giving Fr. 16a (38 mg) which was 
subjected to RP-HPLC (MeOH/ $\left.\mathrm{H}_{2} \mathrm{O} / \mathrm{CH}_{3} \mathrm{CN}, 55: 40: 5\right)$, yielding Fr. $16 \mathrm{~b}(10 \mathrm{mg})$ that was further purified by RP-HPLC (MeOH/ $\left.\mathrm{H}_{2} \mathrm{O} / \mathrm{CH}_{3} \mathrm{CN}, 55: 40: 5\right)$ furnishing compounds 2 (4 mg) and 3 (2 mg).

Juncenolide $\mathrm{M}(\mathbf{1})$ : colorless amorphous solid; $[\alpha]_{\mathrm{D}}{ }^{25}=-42\left(c 0.05, \mathrm{CH}_{2} \mathrm{Cl}_{2}\right)$; UV $(\mathrm{MeOH})$ : 221 (3.20); IR (neat): 3402 (OH), 2930, 2853, 1779 (C=O $\gamma$-lactone), 1741 (C=O ester) cm ${ }^{-1} ;{ }^{1} \mathrm{H}-\mathrm{NMR}$ $\left(300 \mathrm{MHz}, \mathrm{CDCl}_{3}\right)$ data, see Table $1 ;{ }^{13} \mathrm{C}-\mathrm{NMR}\left(75 \mathrm{MHz}, \mathrm{CDCl}_{3}\right.$ ) data, see Table 2; HR-ESI-MS $[\mathrm{M}+\mathrm{Na}]^{+} m / z 621.1711$ (calcd. 621.1715, $\mathrm{C}_{28} \mathrm{H}_{35} \mathrm{ClO}_{12} \mathrm{Na}$ ).

Juncenolide $\mathrm{N}(2)$ : colorless amorphous solid; $[\alpha]_{\mathrm{D}}{ }^{25}=-60\left(c 0.05, \mathrm{CH}_{2} \mathrm{Cl}_{2}\right)$; UV (MeOH): 204 (3.90); IR (neat): $3481(\mathrm{OH}), 1772\left(\mathrm{C}=\mathrm{O} \gamma\right.$-lactone), $1732(\mathrm{C}=\mathrm{O}$ ester $) \mathrm{cm}^{-1} ;{ }^{1} \mathrm{H}-\mathrm{NMR}\left(400 \mathrm{MHz}, \mathrm{CDCl}_{3}\right)$ data, see Table 1; ${ }^{13} \mathrm{C}-\mathrm{NMR}\left(100 \mathrm{MHz}, \mathrm{CDCl}_{3}\right)$ data, see Table 2; HR-ESI-MS $[\mathrm{M}+\mathrm{Na}]^{+} \mathrm{m} / z, 473.2155$ (calcd. 473.2151, $\mathrm{C}_{24} \mathrm{H}_{34} \mathrm{O}_{8} \mathrm{Na}$ ).

Juncenolide $\mathrm{O}(3)$ : colorless amorphous solid; $[\alpha]_{\mathrm{D}}^{25}=+4\left(c 0.05, \mathrm{CH}_{2} \mathrm{Cl}_{2}\right) ; \mathrm{UV}(\mathrm{MeOH}): 220$ (3.80), 205 (3.90); IR (neat): $3423(\mathrm{OH}), 3020,2921,2850,1780$ (C=O $\gamma$-lactone), 1738 (C=O ester) cm ${ }^{-1}$; ${ }^{1} \mathrm{H}-\mathrm{NMR}\left(400 \mathrm{MHz}, \mathrm{CDCl}_{3}\right)$ data, see Table $1 ;{ }^{13} \mathrm{C}-\mathrm{NMR}\left(100 \mathrm{MHz}, \mathrm{CDCl}_{3}\right)$ data, see Table 2; HR-ESI-MS [M + Na $]^{+} m / z$, 17.2212 (calcd. 617.2210, $\mathrm{C}_{29} \mathrm{H}_{38} \mathrm{O}_{13} \mathrm{Na}$ ).

\subsection{Anti-Inflammatory Assays}

Neutrophils were obtained by means of dextran sedimentation and Ficoll centrifugation. Superoxide generation and elastase release were carried out according to a procedure described previously [20]. Superoxide anion production was assayed by monitoring the superoxide dismutase-inhibitable reduction of ferricytochrome $c$. Elastase release experiments were performed using $\mathrm{MeO}$-Suc-Ala-Ala-Pro-Valp-nitroanilide as the elastase substrate. Genistein was used as a positive control.

\section{Conclusions}

Three new diterpenoids, named juncenolides $\mathrm{M}-\mathrm{O}(\mathbf{1}-\mathbf{3})$, were isolated from the Taiwanese gorgonian Junceella juncea Pallas. Compound $\mathbf{1}$ is a new chlorinated briarane, compound $\mathbf{2}$ is a new brierane with a free hydroxy at C-2, while compound $\mathbf{3}$ contains a rare methyl ester at C-5. The anti-inflammatory activities tested on superoxide anion generation and elastase release by human neutrophils in response to FMLP/CB were evaluated. As a result, compounds $\mathbf{2}$ and $\mathbf{3}$ showed moderate inhibitory activities against elastase release at $10 \mu \mathrm{g} / \mathrm{mL}$.

\section{Acknowledgements}

The authors thank the National Science Council, Taiwan (grant No. NSC-100-2113-M-002-0013) for providing financial support.

\section{References}

1. Sung, P.-J.; Gwo, H.-H.; Fan, T.-Y.; Li, J.-J.; Dong, J.; Han, C.-C.; Wu, S.-L.; Fang, L.-S. Natural product chemistry of gorgonian corals of the genus Junceella. Biochem. Syst. Ecol. 2004, 32, 185-196. 
2. Berrue, F.; Kerr, R.G. Diterpenes from gorgonian corals. Nat. Prod. Rep. 2009, 26, 681-710.

3. Sung, P.-J.; Pai, C.-H.; Su, Y.-D.; Hwang, T.-L.; Kuo, F.-W.; Fan, T.-Y.; Li, J.-J. New 8-hydroxybriarane diterpenoids from the gorgonians Junceella juncea and Junceella fragilis. Tetrahedron 2008, 64, 4224-4232.

4. Wang, S.-S.; Chen, Y.-H.; Chang, J.-Y.; Hwang, T.-L.; Chen, C.-H.; Khalil, A.T.; Shen, Y.-C. Juncenolides $\mathrm{H}-\mathrm{K}$, new briarane diterpenoids from Junceella juncea. Helv. Chim. Acta 2009, 92, 2092-2100.

5. Qi, S.-H.; Zhang, S.; Huang, H.; Xiao, Z.-H.; Huang, J.-S.; Li, Q.-X. New briaranes from the south China sea gorgonian Junceella juncea. J. Nat. Prod. 2004, 67, 1907-1910.

6. Qi, S.-H.; Zhang, S.; Qian, B.-Y.; Xiao, Z.-H.; Li, M.-Y. Ten new antifouling briarane diterpenoids from the south China sea gorgonian Junceella juncea. Tetrahedron 2006, 62, 9123-9130.

7. Qi, S.-H.; Zhang, S.; Qian, B.-Y. Antifeedant and antifouling briaranes from the South China Sea gorgonian Junceella juncea. Chem. Nat. Compd. 2009, 45, 49-54.

8. Shen, Y.-C.; Lin, Y.-C.; Chiang, M.Y. Juncenolide A, a new briarane from the Taiwanese gorgonian Junceella juncea. J. Nat. Prod. 2002, 65, 54-56.

9. Shen, Y.-C.; Lin, Y.-C.; Ko, C.-L.; Wang, L.-T. New briarane from the Taiwanese gorgonian Junceella juncea. J. Nat. Prod. 2003, 66, 302-305.

10. Shen, Y.-C.; Lin, Y.-C.; Huang, Y.-L. Juncenolide E, a new briarane from Taiwanese gorgonian Junceella juncea. J. Chin. Chem. Soc. 2003, 50, 1267-1270.

11. Lin, Y.-C.; Huang, Y.-L.; Khalil, A.T.; Chen, M.-H.; Shen, Y.-C. Juncenolides F and G, two new briarane diterpenoids from Taiwanese gorgonian Junceella juncea. Chem. Pharm. Bull. 2005, 53, 128-130.

12. Anjaneyulu, A.S.R.; Rao, N.S.K. Juncins G and H: New briarane diterpenoids of the Indian Ocean gorgonian Junceella juncea Pallas. J. Chem. Soc. Perkin Trans. I 1997, doi:10.1039/A604271F.

13. Anjaneyulu, A.S.R.; Rao, V.L.; Sastry, V.G.; Venugopal Mukku, J.R.V.; Schmitz, F.J. Juncins I-M, five new briarane diterpenoids from the Indian Ocean gorgonian Junceella juncea Pallas. J. Nat. Prod. 2003, 66, 507-510.

14. Sung, P.-J.; Fan, T.-Y.; Fang, L.-S.; She, J.-H.; Wu, S.-L.; Wang, G.-H.; Lin, M.-R. Juncin N, a new briarane-type diterpenoid from the gorgonian coral Junceella juncea. Heterocycles 2003, 61, 587-592.

15. Murthy, Y.L.N.; Mallika, D.; Rajack, A.; Reddy, G.D. A new antifungal briarane diterpenoid from the gorgonian Junceella juncea Pallas. Bioorg. Med. Chem. Lett. 2011, 21, 7522-7525.

16. He, H.-Y.; Faulkner, D.J. New chlorinated diterpenes from the gorgonian Junceella gemmacea. Tetrahedron 1991, 47, 3271-3280.

17. Hamann, M.T.; Harrison, K.N.; Carroll, A.R.; Scheuer, P.J. Briarane diterpenes from Micronesian gorgonians. Heterocycles 1996, 42, 325-331.

18. Subrahmanyam, C.; Kulatheeswaran, R.; Ward, R.S. Briarane diterpenes from the Indian Ocean gorgonian Gorgonella umbraculum. J. Nat. Prod. 1998, 61, 1120-1122.

19. Sheu, J.-H.; Chen, Y.-P.; Hwang, T.-L.; Chiang, M.Y.; Fang, L.-S.; Sung, P.-J. Junceellolides J-L, 11,20-epoxybriaranes from the gorgonian coral Junceella fragilis. J. Nat. Prod. 2006, 69, 269-273. 
20. Liaw, C.-C.; Shen, Y.-C.; Hwang, T.-L.; Kuo, Y.-H.; Khalil, A.T. Frajunolides E-K, briarane diterpenes from Junceella fragilis. J. Nat. Prod. 2008, 71, 1551-1556.

Samples Availability: Available from the authors.

(C) 2012 by the authors; licensee MDPI, Basel, Switzerland. This article is an open access article distributed under the terms and conditions of the Creative Commons Attribution license (http://creativecommons.org/licenses/by/3.0/). 